\title{
Mechanochemical and microwave treatment of precipitated zirconium dioxide and study of its physical-chemical, thermal and photocatalytic properties
}

\author{
Karolina Kucio $^{1}$ (D) Volodymyr Sydorchuk ${ }^{2} \cdot$ Svitlana Khalameida $^{2} \cdot$ Barbara Charmas $^{1}$
}

Received: 28 March 2020 / Accepted: 21 September 2020 / Published online: 13 October 2020

(c) The Author(s) 2020

\begin{abstract}
The effects of the microwave treatment (MWT) and mechanochemical treatment (MChT) on the structure and physicochemical properties of precipitated zirconium oxide were investigated. The obtained materials were characterized using the $\mathrm{N}_{2}$ adsorption/desorption, thermogravimetry (TG, DTG, DTA), XRD and UV-Vis/DRS methods. Photocatalytic properties of the samples were also studied as regards the rhodamine $\mathrm{B}(\mathrm{RhB})$ degradation in the aqueous solution. The results show that the microwave and MChT, differing in mill rotation speed, temperature or treatment media, causes significant changes in the porous structure of the obtained samples. In most samples, the specific surface area increase was observed. The DTA and XRD results showed the formation of crystalline structure during MWT. As follows from the investigations, each way of modification results in the shift of the absorption edge toward higher wavelength values and causes photocatalytic degradation of RhB under UV irradiation and makes the obtained materials effective photocatalysts in the visible region.
\end{abstract}

Keywords Zirconium oxide $\cdot$ Microwave treatment $\cdot$ Mechanochemical treatment $\cdot$ Porous structure $\cdot$ Thermal analysis . Photocatalysis

\section{Introduction}

Zirconium dioxide is a versatile material. As this oxide can be obtained in a highly dispersed state (as non-porous and porous powders or porous xerogels), it is widely applied as the catalysts, the adsorbent or the support for catalysts [1-4]. Its use as a photocatalyst is confined by a large band gap: 3.5-5.0 eV depending on preparation methods

Karolina Kucio

karolina.kucio@poczta.umcs.lublin.pl

Volodymyr Sydorchuk

bilychi@ukr.net

Svitlana Khalameida

svkhal@ukr.net

Barbara Charmas

barbara.charmas@poczta.umcs.lublin.pl

1 Institute of Chemical Sciences, Faculty of Chemistry, Maria Curie Skłodowska University, Maria Curie-Skłodowska Sq. 3, 20-031 Lublin, Poland

2 Institute for Sorption and Problems of Endoecology, NAS of Ukraine, Naumova Street 13, Kyiv 03164, Ukraine and calcination conditions [5-8]. Therefore, $\mathrm{ZrO}_{2}$ exhibits photocatalytic activity only under UV-irradiation [8-10]. All these applications require certain crystal structure and electronic characteristics as well as developed specific surface area and porous structure of $\mathrm{ZrO}_{2}$. The disadvantages of zirconium dioxide obtained by conventional methods (such as precipitation, sol-gel) are a significant content of micropores and an underdeveloped mesoporous structure. Modification of precipitated oxides allows to control porous structure parameters. The hydrothermal method is the most effective for preparation of crystalline $\mathrm{ZrO}_{2}$ with a developed mesoporous structure. The effect of classical hydrothermal treatment (in autoclaves) on zirconium dioxide structure was earlier studied by Chertov and co-workers as well as Sharygin and co-workers. These results are summarized in the reviews $[11,12]$.

A similar effect but in a shorter time can be achieved using the hydrothermal treatment with microwave heating (microwave treatment, MWT) [13-15]. As well hydrothermal conditions are satisfied during the mechanochemical treatment (MChT) in water [16, 17]. Additional possibilities for adjusting the parameters of the porous structure are provided by modification in the wet gel stage before drying 
$[11,18]$. This was exemplarily confirmed using oxides and phosphates [19-22]. Moreover, the efficiency of MWT and MChT application for regulation of physical-chemical properties of other semiconductor oxides was demonstrated in the studies [20, 23-26]. The analysis of the literature data shows that oxides with different characteristics and improved photocatalytic and adsorption properties can be obtained by varying the treatment conditions.

Taking into account the results obtained in those papers, combination of the two approaches (MWT and MChT as well as their use in the wet gel stage) is encouraging for precipitated $\mathrm{ZrO}_{2}$. Moreover, the effect of MWT and MChT on the porous structure of zirconium dioxide has not been reported before.

The aim of this paper was to study the effect of microwave (MWT) and mechanochemical treatment (MChT) on the porous, crystalline and electronic structure of the precipitated $\mathrm{ZrO}_{2}$. The changes in the photocatalytic activity of the obtained samples as a result of those in the physicochemical characteristics were also examined.

\section{Experimental}

\section{Synthesis of $\mathrm{ZrO}_{2}$}

The gelatinous precipitate (coagel) of $\mathrm{ZrO}_{2}$ was prepared by applying the common procedure: the gradual addition $\left(1 \mathrm{~mL} \mathrm{~min}^{-1}\right)$ of $10 \%$ aqueous $\mathrm{NH}_{4} \mathrm{OH}$ solution to the $0.2 \mathrm{M}$ solution of $\mathrm{ZrOCl}_{2} \cdot 8 \mathrm{H}_{2} \mathrm{O}$ with vigorous stirring. At the end of precipitation, the $\mathrm{pH}$ value was 5 . The coagel was ripened in the mother liquor for $12 \mathrm{~h}$, then it was washed with distilled water until a negative reaction toward $\mathrm{Cl}^{-}$ions took place. Finally, coagel was compacted on the filter to a moisture content of about $85 \% \mathrm{w} / \mathrm{w}$. It was granulated by extrusion and dried at $20{ }^{\circ} \mathrm{C}$ for $30 \mathrm{~h}$ for preparation of xerogel. Part of the wet gel (coagel) was subjected to MWT and MChT before granulation and drying.

\section{Procedures of $\mathrm{ZrO}_{2}$ modification}

\section{Microwave treatment (MWT)}

The modification processes were conducted using the NANO 2000 high-pressure reactor (Plazmatronika, Poland, $650 \mathrm{~W}$ ). The temperature and time of treatment duration were 150 and $190{ }^{\circ} \mathrm{C}$ and $0.5 \mathrm{~h}$, respectively. The pressure was 1 and $1.5 \mathrm{MPa}$. About $35 \mathrm{~g}$ of the initial wet coagel was placed in a quartz tube and inserted in the reactor with $20 \mathrm{~mL}$ of water. After modification, the material was dried at $20{ }^{\circ} \mathrm{C}$ for $24 \mathrm{~h}$. As a result, the materials designated: $\mathrm{MWT}_{\text {gel- } 150^{\circ} \mathrm{C}}$ and $\mathrm{MWT}_{\mathrm{gel}-190^{\circ} \mathrm{C}}$ were obtained.

\section{Mechanochemical treatment (MChT)}

The MChT was conducted using a planetary ball mill Pulverisette 7 Premium Line (Fritsch, Germany). Milling was performed in both air atmosphere and water. The container and milling balls were made of $\mathrm{Si}_{3} \mathrm{~N}_{4} .25$ balls of $10 \mathrm{~mm}$ diameter (total balls mass was $40 \mathrm{~g}$ ) were used. The mass of loaded wet gel and dried xerogel was $42 \mathrm{~g}$ and $5 \mathrm{~g}$, respectively. $35 \mathrm{~mL}$ of water was added into the vessel when the xerogel was subjected to MChT in water. The MChT was performed at the mill rotation speeds: 200, 300, 500, 600 and $800 \mathrm{rpm}$ for $0.5 \mathrm{~h}$. After modification, the material was dried at $20^{\circ} \mathrm{C}$ for $24 \mathrm{~h}$. The type of modification, type of starting material and modification conditions are given in the sample designations, e.g., $\mathrm{MChT}_{\text {gel-600 rpm }}$ (mechanochemical treatment of coagel at $600 \mathrm{rpm}$ ), $\mathrm{MChT}_{\text {xerogels/water-300 } \mathrm{rpm}}$ (mechanochemical treatment of xerogels with the water addition at $300 \mathrm{rpm})$, etc.

In addition, the initial $\mathrm{ZrO}_{2}$ xerogel was subjected to the thermal modification at $400{ }^{\circ} \mathrm{C}$ for $5 \mathrm{~h}$ (the sample desig-

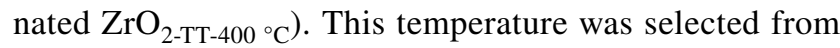
the DTA-TG data.

\section{Characterization methods}

\section{Nitrogen adsorption/desorption}

The nitrogen isotherms of adsorption-desorption were obtained using an automatic gas adsorption analyzer ASAP $2405 \mathrm{~N}$ (Micromeritics Instrument Corp., USA) after outgassing of the samples at $150{ }^{\circ} \mathrm{C}$ for $2 \mathrm{~h}$. The specific surface area $S_{\mathrm{BET}}$, mesopores volume $\left(V_{\mathrm{me}}\right)$ and micropores volume $\left(V_{\mathrm{mi}}\right)$ were calculated from these isotherms using the BET, BJH and t-plot methods, respectively [20]. The sorption pore volume $V_{\mathrm{s}}$ was determined at a relative pressure $p / p_{0}$ close to 1 . The total pore volume $V_{\Sigma}$ was determined by means of impregnation of the dried samples (drying at $150{ }^{\circ} \mathrm{C}$ for $2 \mathrm{~h}$ ) with liquid water. This is so-called the incipient wetness method [27]. The sorption pore volume $\mathrm{V}_{\mathrm{s}}$ includes the volume of micro- $V_{\mathrm{mi}}$ and mesopores $V_{\mathrm{me}}$, which can be filled during sorption from the vapour phase. Macropores, on the other hand, are filled applying liquid impregnation. Therefore, the volume of macropores $V_{\mathrm{ma}}$ is calculated as the difference $V_{\Sigma}-V_{\mathrm{s}}$ [28-30]. The curves of pore size distribution (PSD) were plotted using the desorption branches of isotherms [28]. The pore radius $R_{\mathrm{p}}$ was determined from the PSD curves.

\section{XRD}

The initial $\mathrm{ZrO}_{2}$ and the materials obtained after modification were studied by the X-ray powder diffraction (XRD, Empyrean, USA) using the Philips PW 1830 diffractometer with $\mathrm{CuK}_{\alpha}$ radiation. The X-ray patterns were scanned in the $2 \Theta$ 
range of $10^{\circ}-60^{\circ}$ with a step $0.02^{\circ}$. The crystallite size for $\mathrm{ZrO}_{2}$ was calculated according to the Scherrer formula using the reflex at $30.2^{\circ}$.

\section{DTA-TG}

The curves of DTA and TG were recorded using the Derivatograph-C apparatus (F.Paulik, J.Paulik, L.Erdey) in the temperature range of $20-800{ }^{\circ} \mathrm{C}$ at a heating rate of $10 \% \mathrm{~min}$. The initial sample mass was 30 or $200 \mathrm{mg}$.

\section{UV-Vis diffuse reflectance spectroscopy}

The diffuse reflectance UV-Vis/DRS spectra of the samples were registered using the UV-Vis/DRS Lambda $35 \mathrm{UV}-\mathrm{Vis}$ spectrometer (Perkin-Elmer Instruments). $\mathrm{MgO}$ was used as reference sample. The spectra were recorded in the range 200 $-600 \mathrm{~nm}$. The absorption edge $\lambda$ of the obtained samples was determined using spectra plotted in the Kubelka-Munk equation coordination. The value of the band gap $\mathrm{E}_{\mathrm{g}}$ was calculated from the Planck equation:

$E_{\mathrm{g}}=1239.5 / \lambda$

\section{Photocatalytic test}

Photocatalytic activity of the selected samples was tested in relation to the aqueous solution of rhodamine $\mathrm{B}(\mathrm{RhB}$, $C_{0}=0.5 \cdot 10^{-5} \mathrm{~mol} \mathrm{~L}^{-1}$ ) in the range of ultraviolet (UV) and visible (Vis) radiation. High-intensity discharge Na-lamp GE Lucalox (Hungary, $70 \mathrm{~W}$ ), which irradiates solely in the visible region, was used as the Vis light source while photodegradation using the UV light was conducted in a quartz reactor using the $\mathrm{Hg}$ lamp $(254 \mathrm{~nm}, 30 \mathrm{~W})$. The ratio of catalyst $(\mathrm{mg})$ to the solution $(\mathrm{mL})$ was $1: 1$. The solution was mixed with the weighed sample using a magnetic stirrer without light access for $60 \mathrm{~min}$ to determine the balance of adsorption / desorption of the dye on the photocatalyst surface. During the specific time about $3 \mathrm{~mL}$ of the reaction mixture was collected, centrifuged (10 min, $8000 \mathrm{rpm}$ ) and analyzed using the spectrophotometer (Lambda 35, Perkin-Elmer Instruments) at $\lambda=554 \mathrm{~nm}$. The photodegradation constants $K_{\mathrm{d}}^{\mathrm{UV}}$ and $K_{\mathrm{d}}^{\mathrm{Vis}}$ were calculated on the basis of the concentration changes of the dye solution after the adsorption/ desorption equilibrium establishment.

\section{Results and discussion}

\section{Crystal structure}

It is well known that $\mathrm{ZrO}_{2}$ exists in three polymorphs at the atmospheric pressure [5]: the monoclinic, the tetragonal, and the cubic fluorite, denoted as $\mathrm{m}-$, $\mathrm{t}-$, and $\mathrm{c}-\mathrm{ZrO}_{2}$, respectively. However, zirconium dioxide precipitated from the aqueous solution is often X-ray amorphous. Figure 1 presents the patterns of the initial coagel $\mathrm{iniZrO}_{2}$ as well as the materials after thermal $\left(\mathrm{ZrO}_{2-\mathrm{TT}-400^{\circ} \mathrm{C}}\right)$ and microwave $\left(\mathrm{MWT}_{\text {gel-150 }}{ }^{\circ} \mathrm{C}\right.$ and $\left.\mathrm{MWT}_{\text {gel-1 } 190{ }^{\circ} \mathrm{C}}\right)$ treatment. As the initial material $\left(\mathrm{iniZrO}_{2}\right)$, the samples after $\mathrm{MChT}$ were X-ray amorphous (these diffractograms were not shown). This experimental fact is in full agreement with the general tendencies of changes in the crystal structure during the mechanochemical treatment. This concerns the disordering effect of MChT on the structure of oxides in general [20-23, 25, 26] and zirconium dioxide in particular [31]. Therefore, it is unlikely that crystallization of $\mathrm{ZrO}_{2}$ can occur due to the milling of amorphous form.

On the contrary, after the thermal and microwave treatment the appearance of peaks for crystalline $\mathrm{ZrO}_{2}$ was observed. That indicates the formation of the zirconium crystalline structure. The XRD pattern for a sample treated at $400{ }^{\circ} \mathrm{C}\left(\mathrm{ZrO}_{2-\mathrm{TT}-400^{\circ} \mathrm{C}}\right)$ indicates that this material has a practically pure tetragonal phase as evidenced by the peaks located at $2 \theta=30.2^{\circ}$ (the most intense) and $2 \theta=35.2^{\circ}$ and $50.6^{\circ}$ (JCPDS No. 50-1089). Thermal treatment promotes the crystallization process and the growth of $\mathrm{ZrO}_{2}$ crystal-

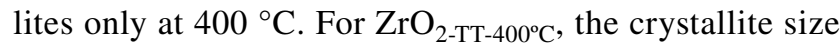
was $15 \mathrm{~nm}$. The patterns recorded for the samples after MWT indicate the presence of both tetragonal $\left(2 \theta=30.2^{\circ}\right.$, $35.2^{\circ}$ and $\left.50.6^{\circ}\right)$ and monoclinic $\left(2 \theta=24.4^{\circ}\right.$ and $\left.28.2^{\circ}\right)$ phases but with a predominance of $\mathrm{t}-\mathrm{ZrO}_{2}$ phase. The comparison of the $\mathrm{MWT}_{\text {gel- } 150}{ }^{\circ} \mathrm{C}$ and $\mathrm{MWT}_{\text {gel- } 190}{ }^{\circ} \mathrm{C}$ patterns indicates that the use of a higher MWT temperature results in the development of both monoclinic and tetragonal crystalline phases (Fig. 1). The crystallite sizes for

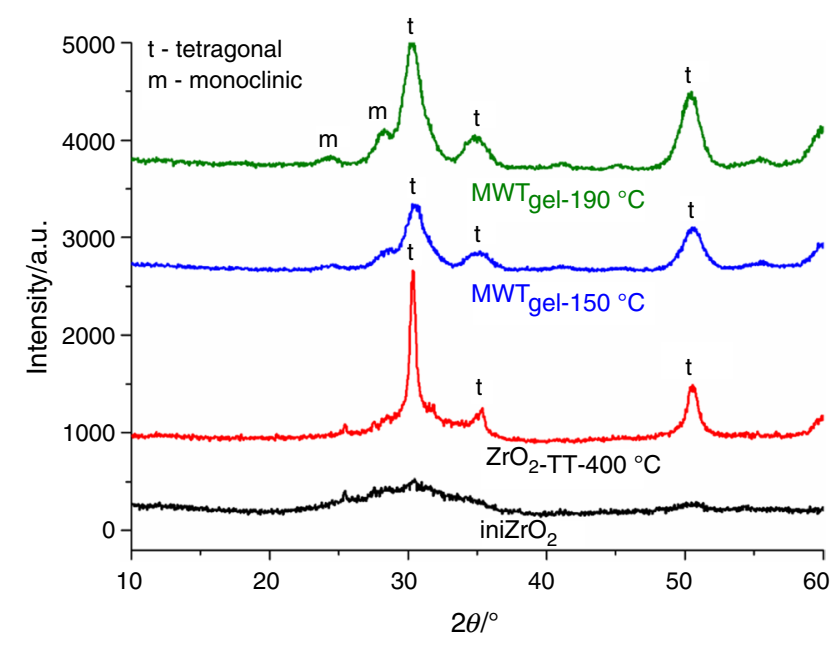

Fig. 1 The XRD patterns of iniZrO ${ }_{2}$ and the samples after the thermal $\left(\mathrm{ZrO}_{2-\mathrm{TT}-400^{\circ} \mathrm{C}}\right)$ and microwave treatment $\left(\mathrm{MWT}_{\text {gel-150 }}{ }^{\circ} \mathrm{C}\right.$ and $\left.\mathrm{MWT}_{\text {gel- } 1900^{\circ} \mathrm{C}}\right)$ 
these materials are 5 and $5.5 \mathrm{~nm}$, respectively. Therefore, MWT allows to prepare tetragonal $\mathrm{ZrO}_{2}$ at a lower temperature compared to the thermal treatment. As a result, more dispersed crystalline phase is formed than after the thermal treatment.

\section{Porous structure}

The examples of nitrogen adsorption/desorption isotherms for the tested samples are shown in Fig. 2. As follows from the analysis of the adsorption isotherms course, they are of I and IV types according to the IUPAC classification [29]. The course of the curves for iniZrO ${ }_{2}$ (Fig. 2) indicates that they are type I isotherms without the hysteresis loop. These isotherms are characteristic of the monolayer

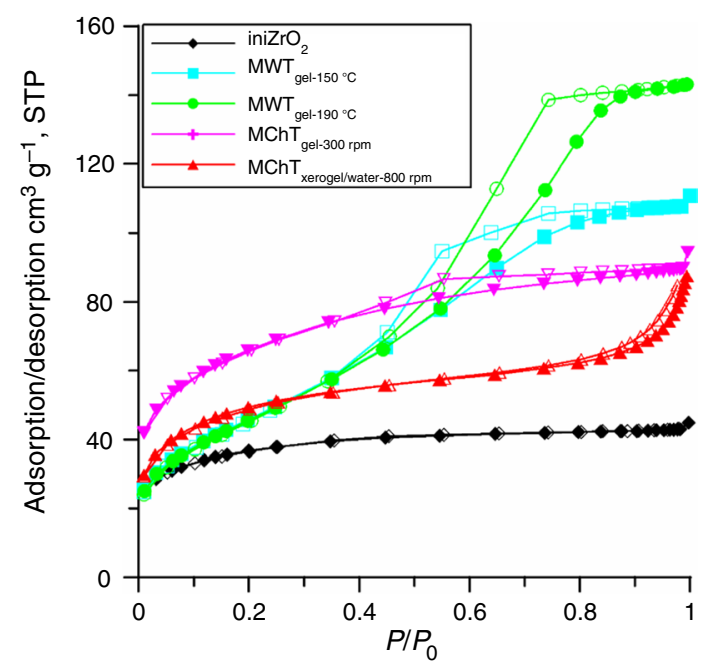

Fig. 2 The low-temperature adsorption/desorption isotherms of nitrogen obtained for the exemplary samples adsorption on the microporous materials [30]. Nonetheless the iniZrO $\mathrm{Zr}_{2}$ sample contains mesopores of the minimal average pore radius, that is $R_{\mathrm{p}}=1.3 \mathrm{~nm}$ (Table 1 ). The course of the isotherms for the materials after modification in the presence of water (Fig. 3) indicates that both the mechanochemical and microwave treatment causes the development of a porous structure. The isotherms are located higher and the hysteresis loops are gradually shifted higher relative to the $p / p_{0}$ axis which indicates the surface and mesoporosity development of the obtained materials. This is the most evident in the case of materials obtained using the microwave energy $\left(\mathrm{MWT}_{\mathrm{gel}-150{ }^{\circ} \mathrm{C}}\right.$ and $\mathrm{MWT}_{\text {gel-1 } 190{ }^{\circ} \mathrm{C}}$ ). The course of the curves for these materials indicates that these are type IV isotherms with developed hysteresis loops of type H2 which are characteristic of mesoporous materials, in the pores of which the phenomenon of capillary condensation is observed. According to Sing et al. [32], the course of these hysteresis shape indicates presence of pores with narrow mouths (ink-bottle pores), relatively uniform channel-like pores, pore network (connectivity) effects. At the same time, MWT leads to removal of micropores by turning them into mesopores (Fig. 2; Table 1). The size of the latter increases to $3.7-4.7 \mathrm{~nm}$. This is caused by mass transfer processes and crystallization of amorphous phase [11]. The latter is accompanied by formation of a denser phase and corresponding generation of additional porosity according to the Pilling-Bedworth ratio [33, 34]. As can be seen using the microwave treatment of coagel (Fig. $2, \mathrm{MWT}_{\text {gel- } 150{ }^{\circ} \mathrm{C}}$ and $\mathrm{MWT}_{\text {gel-1 } 190^{\circ} \mathrm{C}}$ ) resulted in a greater increase in mesoporosity than the use of mechanochemical treatment (Fig. 2, $\mathrm{MChT}_{\text {gel-300 rpm }}$ ). However, the changes in the specific surface area are more significant after MChT of gel (Table 1).

Figure 3 presents the $\mathrm{N}_{2}$ adsorption isotherms for the samples obtained as a result of mechanochemical treatment in the form of dried xerogel (in water or air) using

Table 1 The parameters of the porous structure for some samples

\begin{tabular}{|c|c|c|c|c|c|c|c|}
\hline Sample & $S_{\mathrm{BET}} / \mathrm{m}^{2} \mathrm{~g}^{-1}$ & $V_{\Sigma} / \mathrm{cm}^{3} \mathrm{~g}^{-1}$ & $V_{\mathrm{s}} / \mathrm{cm}^{3} \mathrm{~g}^{-1}$ & $V_{\mathrm{me}} / \mathrm{cm}^{3} \mathrm{~g}^{-1}$ & $V_{\mathrm{mi}} / \mathrm{cm}^{3} \mathrm{~g}^{-1}$ & $V_{\mathrm{ma}} / \mathrm{cm}^{3} \mathrm{~g}^{-1}$ & $R_{\mathrm{p}} / \mathrm{nm}$ \\
\hline iniZrO ${ }_{2}$ & 130 & 0.07 & 0.07 & 0.04 & 0.03 & 0 & 1.3 \\
\hline $\mathrm{MChT}_{\mathrm{gel}-200 \mathrm{rpm}}$ & 199 & 0.19 & 0.10 & 0.06 & 0.04 & 0.09 & 1.35 \\
\hline $\mathrm{MChT}_{\mathrm{gel}-300 \mathrm{rpm}}$ & 264 & 0.18 & 0.14 & 0.10 & 0.04 & 0.04 & 1.35 \\
\hline $\mathrm{MChT}_{\mathrm{gel}-500 \mathrm{rpm}}$ & 251 & 0.20 & 0.16 & 0.12 & 0.04 & 0.04 & 1.45 \\
\hline $\mathrm{MChT}_{\mathrm{gel}-600 \mathrm{rpm}}$ & 255 & 0.24 & 0.15 & 0.12 & 0.03 & 0.09 & 1.6 \\
\hline $\mathrm{MChT}_{\text {gel-800 rpm }}$ & 277 & 0.27 & 0.15 & 0.10 & 0.05 & 0.12 & 1.55 \\
\hline $\mathrm{MChT}_{\text {xerogel /air-200 rpm }}$ & 243 & 0.15 & 0.14 & 0.11 & 0.03 & 0.01 & 1.35 \\
\hline $\mathrm{MChT}_{\text {xerogel/air-300 rpm }}$ & 75 & 0.07 & 0.07 & 0.06 & 0.01 & 0 & $1.3 ; 3.35$ \\
\hline $\mathrm{MChT}_{\text {xerogel/water-200 rpm }}$ & 97 & 0.26 & 0.06 & 0.04 & 0.02 & 0.2 & 1.35 \\
\hline $\mathrm{MChT}_{\text {xerogel} / \text { water-300 rpm }}$ & 86 & 0.23 & 0.07 & 0.06 & 0.01 & 0.16 & $1.35 ; 9.45$ \\
\hline $\mathrm{MChT}_{\text {xerogel} / \text { water }-800 \mathrm{rpm}}$ & 88 & 0.17 & 0.08 & 0.06 & 0.02 & 0.09 & $1.4 ; 7.25$ \\
\hline $\mathrm{MWT}_{\mathrm{gel}-150^{\circ} \mathrm{C}}$ & 164 & 0.23 & 0.17 & 0.17 & 0 & 0.06 & 1.85 \\
\hline $\mathrm{MWT}_{\text {gel- } 190^{\circ} \mathrm{C}}$ & 163 & 0.31 & 0.22 & 0.22 & 0 & 0.09 & 2.35 \\
\hline
\end{tabular}




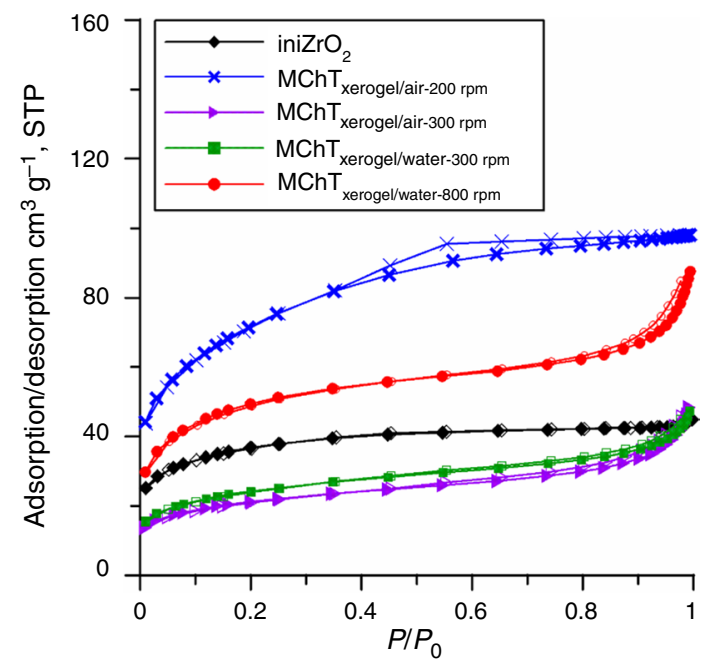

Fig. 3 The low-temperature adsorption/desorption isotherms of nitrogen registered for initial $\mathrm{ZrO}_{2}$ and some samples after the mechanochemical treatment

different mill rotation speeds. Only the isotherms for the samples $\mathrm{MChT}_{\text {xerogels/air-200 rpm }}$ and $\mathrm{MChT}_{\text {xerogel/water-800 rpm }}$ are close to type IV with the developed $\mathrm{H} 2$ and $\mathrm{H} 3$ $\left(\mathrm{MChT}_{\text {xerogels/air-300 rpm }}\right)$ hysteresis loops, respectively [30]. The isotherms for the samples milled at $300 \mathrm{rpm}$ have a poorly pronounced hysteresis loop of type $\mathrm{H} 4$. On this basis, it can be concluded that the modified materials have pores of different shapes: narrow slit-like pores, particles with internal voids of irregular shape and broad size distribution, hollow spaces between the particle walls [32].

In the case of mechanochemical treatment in air, the intensive development of porous structure (Fig. 3) occurs using a slower mill rotation speed $\left(\mathrm{MChT}_{\text {xerogels/air-200 rpm }}\right.$, Fig. 3; Table 1). An increase in the mill rotation speed
$\left(\mathrm{MChT}_{\text {xerogels/air-300 rpm }}\right)$ results in an approximately threefold reduction of $S_{\mathrm{BET}}$ compared to $\mathrm{MChT}_{\text {xerogels/air-200 rpm }}$. An inverse relationship for the mechanically treated samples with the addition of water is observed. In this case, the $S_{\mathrm{BET}}$ of this material decreases as the mill rotation speed increases (Table 1). The dependences of the specific surface area and the total pore volume on the conditions of MWT and MChT (temperature and rotation speed) are shown in Fig. 4a, b.

As can be seen after MChT of $\mathrm{ZrO}_{2}$, mostly in the form of wet gel, the specific surface area $\left(S_{\mathrm{BET}}\right)$ of the obtained materials increased $\left(\mathrm{MChT}_{\text {gel }}\right.$ series) about twice as compared to the surface of the initial material (iniZrO $\mathrm{Z}_{2}$, $S_{\mathrm{BET}}=130 \mathrm{~m}^{2} \mathrm{~g}^{-1}$, Table 1). Such tendency along with the increase in mill rotation speed is observed for the coagel based materials (Fig. 4a; Table 1). The highest $S_{\mathrm{BET}}$ value for the $\mathrm{MChT}_{\text {gel-800 rpm }}$ sample was observed (Table 1, $S_{\mathrm{BET}}=277 \mathrm{~m}^{2} \mathrm{~g}^{-1}$, Fig. 4a). For the discussed materials $\left(\mathrm{MChT}_{\mathrm{gel}}\right.$ series), during the increase in mill rotation speed, the pore volume $\left(V_{\Sigma}, V_{\mathrm{s}}, V_{\mathrm{me}}\right)$ and $R_{\mathrm{p}}$ (Table 1 , Fig. $4 \mathrm{~b}$ ) increase. It should be noted that similar results were earlier obtained for silica, tin dioxide and zirconium phosphate after their MChT [19-21]. It is well known that the specific surface area and pore volume depend on the globules size and their packing density in the skeleton of globular porous solids [29]. Obviously, repackaging of globules occurs only during MChT in the presence of water. An increase in the specific surface area after MWT is due to formation of a more dispersed crystalline phase in the amorphous matrix which is characteristic for hydrothermal conditions [11]. On the contrary, mass transfer processes cause its decrease. Therefore, a resulting effect of increase in the specific surface area at MWT is not as significant as at MChT of wet gels. In the latter case, the processes of crystallization and mass transfer do not play a significant role but those of grinding and repackaging
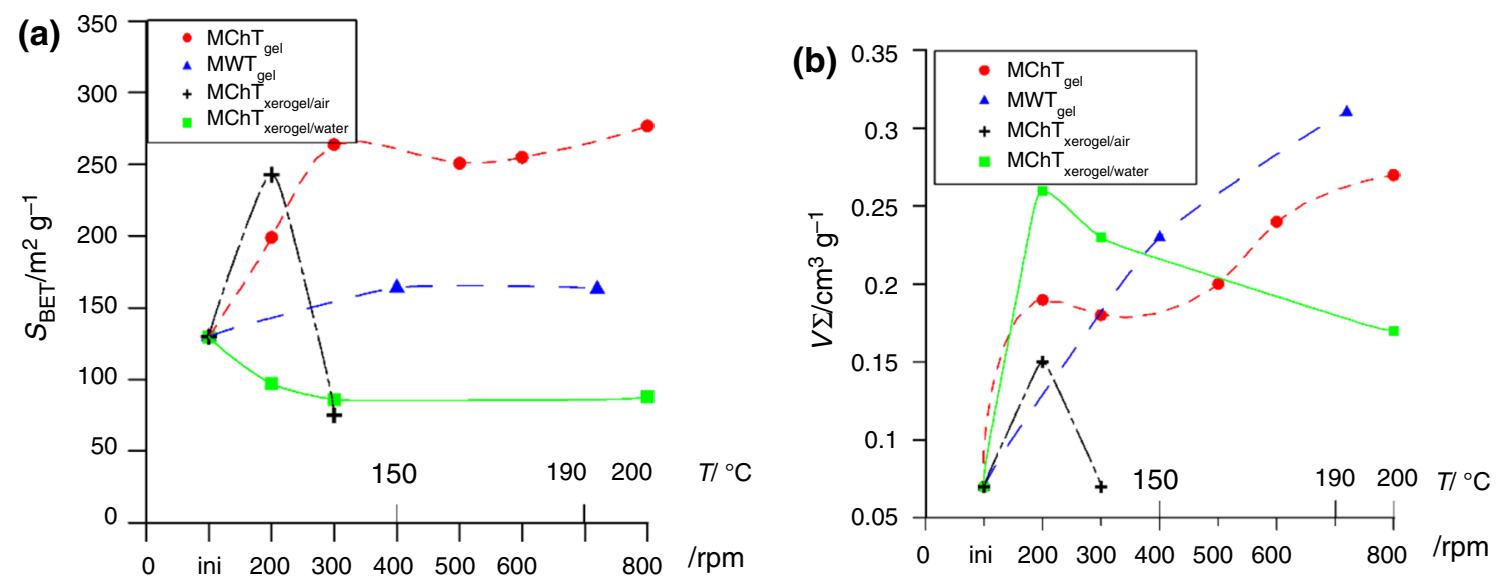

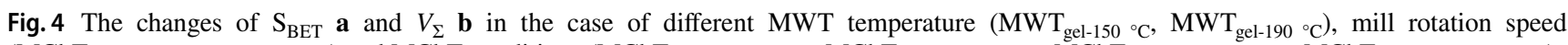
$\left(\mathrm{MChT}_{\text {gel-200, 300, 500, 600, } 800 \mathrm{rpm}}\right)$ and $\mathrm{MChT}$ conditions $\left(\mathrm{MChT}_{\text {xerogel/air-200 rpm }} \mathrm{MChT}_{\text {xerogel/air-300 rpm }} \mathrm{MChT}_{\text {xerogel/water-200 rpm }} \mathrm{MChT}_{\text {xerogel/water-300 rpm }}\right)$ 
globules in the gel skeleton are of remarkable importance. As a result, a more accessible for nitrogen molecules structure, containing meso- and macropores, is formed in the drying stage. The specific surface area obviously increases after MChT in air at the minimal intensity (200 rpm) for the same reason. Reduction in the specific surface area and pore volume values, observed at greater intensity, is due to the destruction of xerogel rigid structure affected by the mechanical forces.

The pore volume distribution curves by their average radius $(\mathrm{dV} / \mathrm{dR}$, Fig. 5a-d) confirm the results presented in Table 1. Most of the obtained materials have a monomodal character. However, the bimodal pore structure was observed as the mill rotation speed increased (Table 1,

(a)

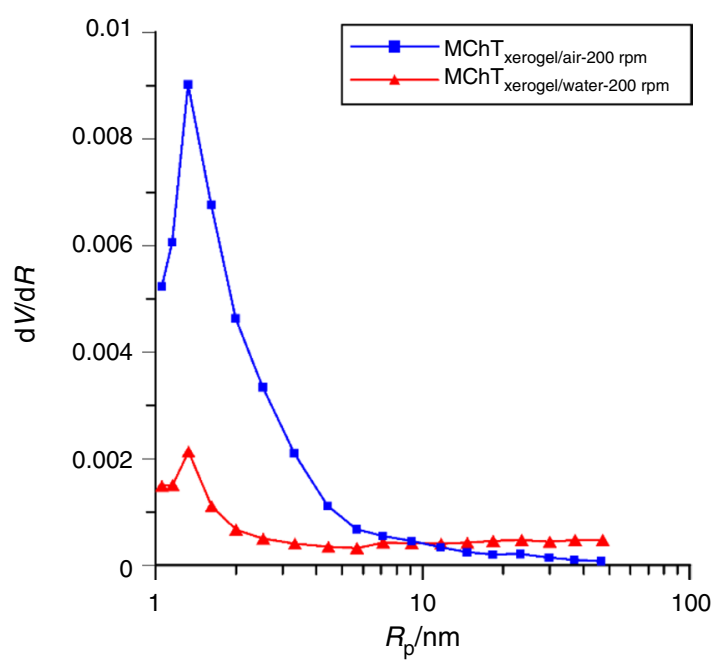

(c)

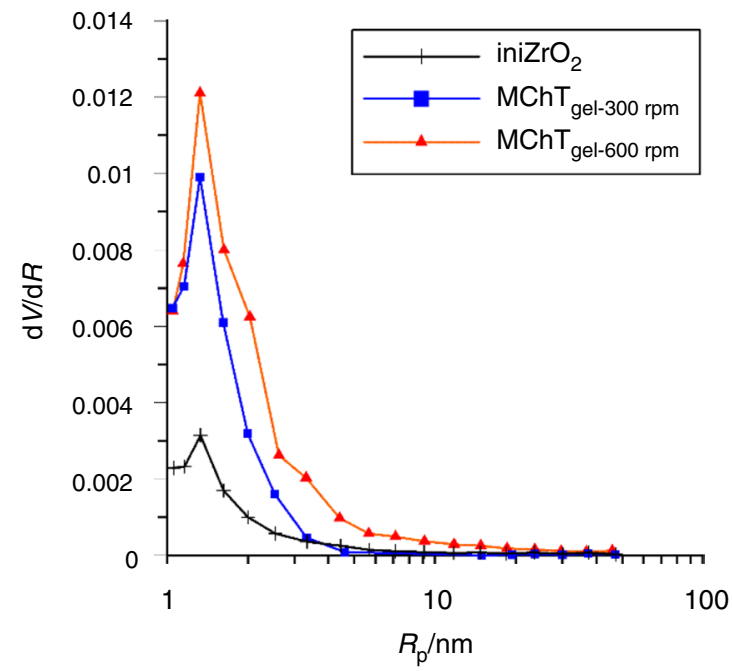

Fig. 5b). In the case of $d V / d R$ curves recorded for the mechanochemically treated samples (both in air and with the addition of water) at $200 \mathrm{rpm}$, one can observe clearly formed maxima indicating the presence of narrow mesopores $\left(R_{\mathrm{p}} \sim 1.3 \mathrm{~nm}\right.$, Fig. 5a). Comparing Figs. 5a and $\mathrm{b}$ formation of pores of differentiated sizes (Fig. 5b) for the xerogel materials can be observed as the mill rotation speed increases.

Figure $5 \mathrm{c}, \mathrm{d}$ presents the pore volume distribution curves relative to their average radii for the samples modified in the form of wet gel. The course of the analyzed curves indicates that the increase in the mill rotation speed (Fig. 5c) causes an increase in the pore volume, the size of which does not change $\left(R_{\mathrm{p}} \sim 1.4 \mathrm{~nm}\right)$. Moreover, one

\section{(b)}

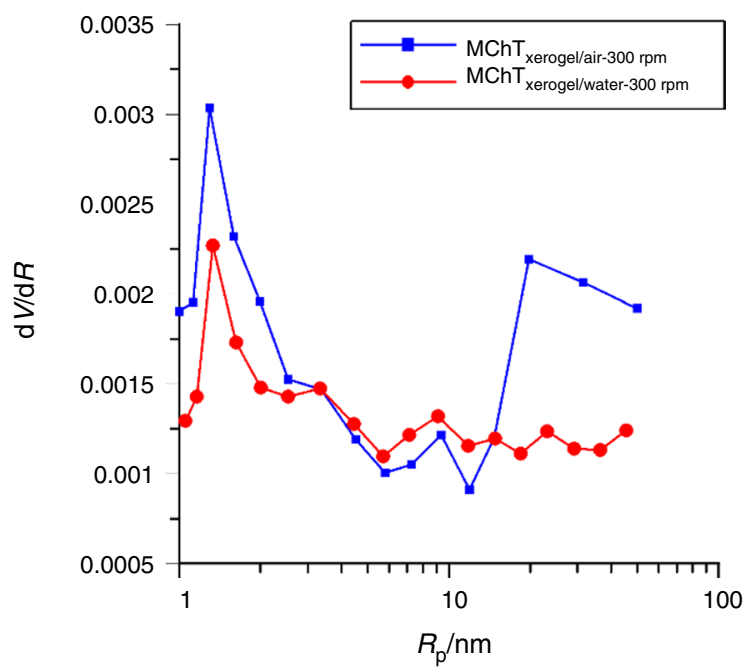

(d)

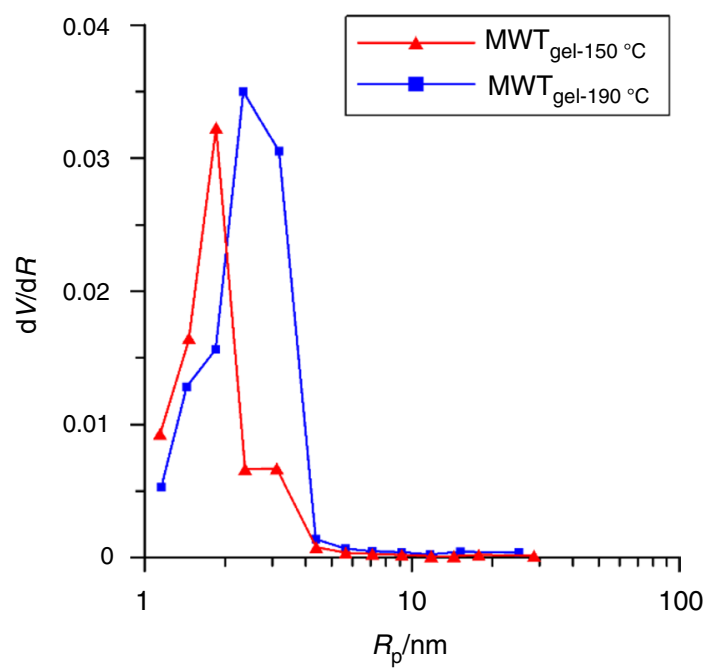

Fig. 5 The pore volume distribution functions $(\mathrm{dV} / \mathrm{dR})$ regarding their radius for some samples (a-d) 
can see that the fraction of pores with a radius greater than $2 \mathrm{~nm}$ increases after MChT of gel. The increase in temperature used during the microwave treatment (Fig. 5d) resulted in both the volume $\left(V_{\Sigma}, V \mathrm{~s}\right)$ and the average pore radius increase (Table 1; Fig. 4b). It should also be noted that modification in the presence of water (MWT and $\mathrm{MChT}$ ) leads to formation of macropores, as indicated by the excess of $V_{\Sigma}$ over $V_{\mathrm{s}}$ (Table 1). This is due to the fact that macropores are filled by means of only liquid impregnation as mentioned above.

\section{DTA-TG measurements}

The results of thermogravimetric analysis complement well and confirm the investigations of the crystalline and porous structure. The curves of DTA-TG-DTG for some selected samples are presented in Fig. 6a-c. Thus, the curves, typical of amorphous zirconium dioxide and discussed in the literature [35-37], were obtained for the initial sample and that milled at $600 \mathrm{rpm}$ in the form of wet gel (Fig. 6a, b). The sharp exoeffects on the DTA curve at 436 and $427^{\circ} \mathrm{C}$, respectively, indicate crystallization of amorphous $\mathrm{ZrO}_{2}$ and confirm the XRD results. The very similar curves recorded for the other milled samples are also $\mathrm{X}$-amorphous. The DTA curve registered for the crystalline sample $\mathrm{MWT}_{\text {gel-190 }}{ }^{\circ} \mathrm{C}$ contains only poorly diffused exoeffects with the maxima at 397 and $473{ }^{\circ} \mathrm{C}$ (Fig. 6c). These effects can be attributed to the crystallization amorphous phase residues and transformation of formed $\mathrm{m}-\mathrm{ZrO}_{2}$ into $\mathrm{t}-\mathrm{ZrO}_{2}$. It should be noted that a much larger sample was used in the measurement compared to the first two samples: $200 \mathrm{mg}$ versus $30 \mathrm{mg}$.

Endoeffects in the temperature range up to $200{ }^{\circ} \mathrm{C}$, which are accompanied by the mass loss $\left(\Delta \mathrm{m}_{20-200}\right)$, are associated with removal of physically adsorbed water from pores. Therefore, the $\Delta \mathrm{m}_{20-200}$ value is directly related to the pore size: the smaller the pore size, the greater the mass loss (a)

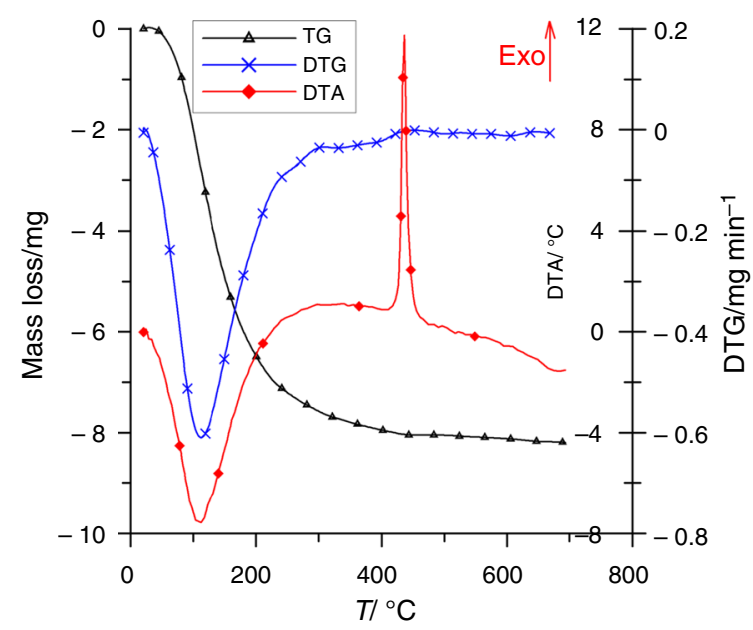

(b)

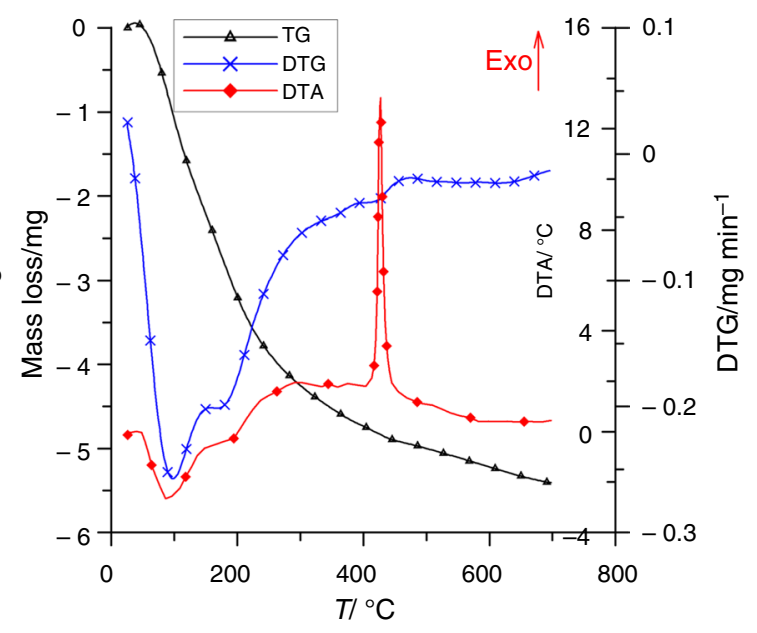

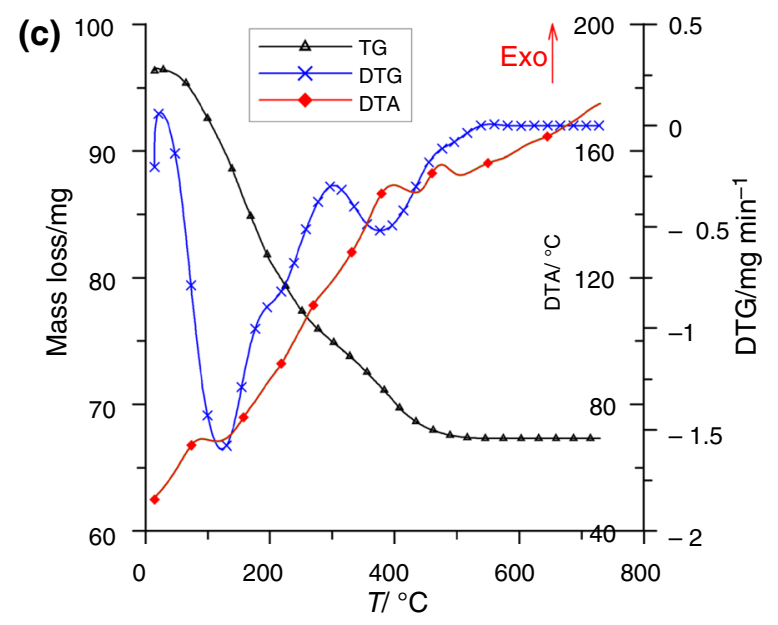

Fig. 6 The curves of DTA, TG and DTG for the initial sample-mass $30 \mathrm{mg}$ a, the sample milled as gel at $600 \mathrm{rpm} \mathrm{MChT}_{\text {gel- } 600 \mathrm{rpm}}-\mathrm{mass} 30 \mathrm{mg}$ b, the sample after MWT gel at $190{ }^{\circ} \mathrm{C}$-mass $200 \mathrm{mg}$ c 
$\Delta \mathrm{m}_{20-200}$. This can be seen comparing the data in Table 1 (column $8, R_{\mathrm{p}}$ ) and Table 2 (column $4, \Delta \mathrm{m}_{20-200}$ ). Two endoeffects are observed for the initial and milled samples (Table 2 , column $2, t_{\text {endo }}$ ): low and high temperature. Obviously they correspond to removal of water from the mesoand micropores, respectively. There is a low-temperature endoeffect only for the sample after MWT since it does not contain micropores.

The second stage of mass loss in the temperature range $200-500{ }^{\circ} \mathrm{C}\left(\Delta \mathrm{m}_{200-500}\right)$ is attributed to the dehydroxylation processes [33, 34]. As can be seen from column 5 of Table 2 , the value of $\Delta \mathrm{m}_{200-500}$ is within $6.4-7.2 \% \mathrm{w} / \mathrm{w}$, almost the same for all studied samples.

\section{Electronic structure}

Figure 7 presents the UV-Vis/DRS spectra recorded for the initial and some modified samples. For the iniZrO $\mathrm{Zr}_{2}$ sample, the absorption edge is at $\lambda=268 \mathrm{~nm}$. As follows, the value of band gap energy was $E_{\mathrm{g}}=4.63 \mathrm{eV}$ (Table 3) which is consistent with the literature data $[6,7]$. Thus, this material shows strong absorption in the UV region (Table 3, Fig. 7). All kinds of modification result in the absorption edge shift toward a longer wavelength-the bathochromic shift $\Delta \lambda$. As a result, narrowing the band gap $E_{\mathrm{g}}$ takes place (Table 3 ). The mill rotation speed has a significant effect on the value of $E_{\mathrm{g}}$. It can be concluded that the increase in mill rotation speed resulted in reduction in band gap energy by $0.79 \mathrm{eV}$ if compare the $E_{\mathrm{g}}$ values for the $\mathrm{MChT}$ xerogel/water-300 rpm and MChT xerogel/water-800 rpm samples (Table 3). Therefore, the maximal value of $\Delta \lambda$ and the minimal value of $E_{\mathrm{g}}$ were obtained for the sample milled in water at $800 \mathrm{rpm}$. It is important that $E_{\mathrm{g}}$ for some modified samples is lower $3.26 \mathrm{eV}$. The latter is a necessary condition for photocatalytic activity at visible light [38].

\section{Photocatalytic properties}

The treatment methods (MChT, MWT) used in the discussed materials resulted in an increase in photocatalytic activity in the UV range compared to the iniZrO ${ }_{2}$. This is evidenced by the values of the rate constants for the rhodamine B $K_{\mathrm{d}}(\mathrm{UV})$ degradation (Table 3 ). The photodegradation rate constants $K_{d}$ were calculated from the slopes of the plots $\ln \left(D / D_{0}\right)-t$ (where $D$ and $D_{0}$ are the values of

Table 2 The results of thermal analysis for the exemplary samples

\begin{tabular}{lllll}
\hline Samples & $t_{\text {endo }}$ & $t_{\text {exo }}$ & $\Delta \mathrm{m}_{20-200}$ & $\Delta \mathrm{m}_{200-500}$ \\
\hline iniZrO $_{2}$ & $110 ; 130$ & 436 & 21.7 & 6.4 \\
$\mathrm{MChT}_{\text {gel-600 rpm }}$ & $90 ; 170$ & 427 & 10.7 & 6.5 \\
$\mathrm{MWT}_{\text {gel-190 }}{ }^{\circ} \mathrm{C}$ & 115 & $397 ; 473$ & 7.7 & 7.2 \\
\hline
\end{tabular}

optical density of RhB solution after time $t$ and dark adsorption, respectively) using the first-order kinetic equation $[8$, $38,39]$. As can be seen, the initial $\mathrm{ZrO}_{2}$ sample showed low activity but its modification promotes enhancement of photocatalytic activities. The greatest UV activity was

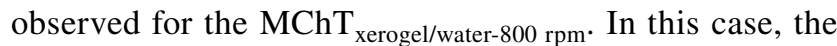
value of $K_{\mathrm{d}}$ was $9.4 \times 10^{-5} \mathrm{~s}^{-1}$ (Table 3). As mentioned above, a shift of the absorption edge toward larger wavelengths and narrowing a band gap was observed also for the modified samples (Fig. 7). Just the $\mathrm{MChT}_{\text {xerogel/water- } 800 \mathrm{rpm}}$ sample has a minimum value of $E_{\mathrm{g}}$. It is interesting that the reference commercial photocatalyst $\mathrm{P}-25\left(\mathrm{TiO}_{2}\right.$ composed of anatase and rutile) $[25,38]$ exhibited higher activity than iniZrO $\mathrm{Z}_{2}$ but lower activity compared with some modified samples of $\mathrm{ZrO}_{2}$. The larger bandgap for P-25 is the main reason for this.

On the other hand, the initial sample of $\mathrm{ZrO}_{2}$ is photocatalytically inactive in the visible region due to its high-value

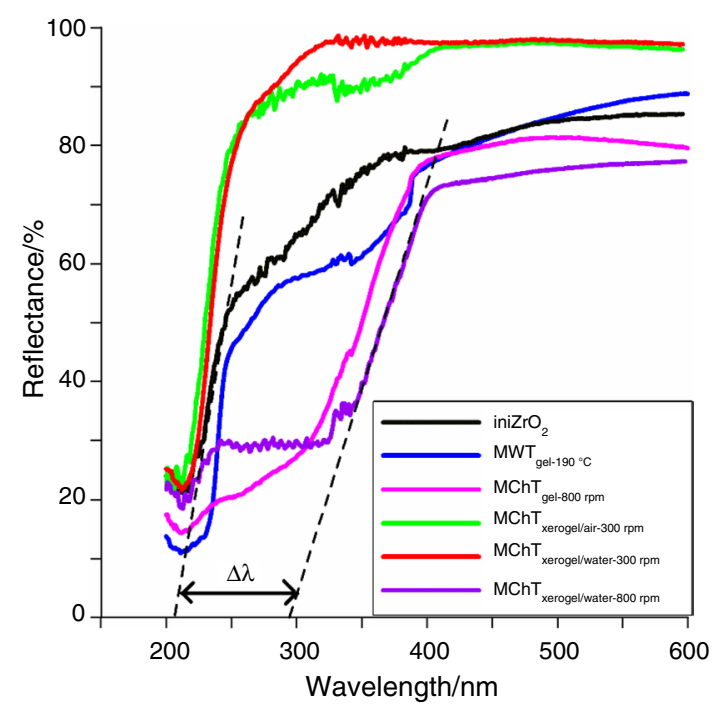

Fig. 7 The UV-VIS diffuse reflectance spectra for the $\mathrm{ZrO}_{2}$ samples

Table 3 The electronic characteristics and photocatalytic activities of some $\mathrm{ZrO}_{2}$ samples

\begin{tabular}{lcclc}
\hline Sample & $\lambda \mathrm{nm}$ & $E_{\mathrm{g}} \mathrm{eV}$ & $\begin{array}{l}K_{\mathrm{d}} \cdot 10^{5} \\
(\mathrm{UV}) \mathrm{s}^{-1} \\
\text { Rhodamine } B\end{array}$ & $\begin{array}{l}K_{\mathrm{d}} \cdot 10^{5}(\mathrm{Vis}) \\
\mathrm{s}^{-1}\end{array}$ \\
\hline $\mathrm{iniZrO}_{2}$ & 268 & 4.63 & 2.2 & - \\
$\mathrm{MChT}_{\text {gel-800 rpm }}$ & 401 & 3.09 & 8.8 & 6.2 \\
$\mathrm{MWT}_{\text {gel-190 }}{ }^{\circ} \mathrm{C}$ & 376 & 3.31 & 7.0 & 2.6 \\
$\mathrm{MChT}_{\text {xerogel/air-300 rpm }}$ & 363 & 3.42 & 5.7 & 1.2 \\
$\mathrm{MChT}_{\text {xerogel/water-300 rpm }}$ & 325 & 3.85 & 3.1 & 0.3 \\
$\mathrm{MChT}_{\text {xerogel/water-800 rpm }}$ & 405 & 3.06 & 9.4 & 5.0 \\
$\mathrm{P}-25$ & 376 & 3.30 & 6.1 & 1.1 \\
\hline
\end{tabular}




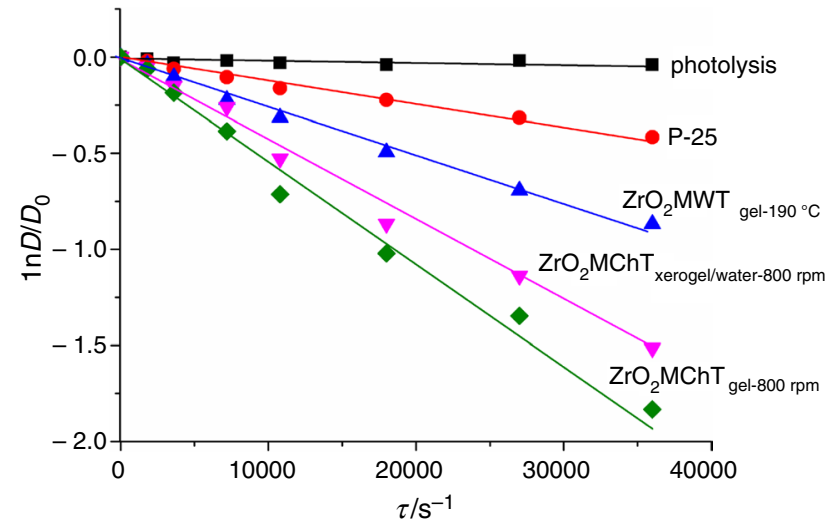

Fig. 8 Kinetic curves of RhB degradation under visible irradiation

band gap, whereas the samples milled at $800 \mathrm{rpm}$ show the maximal photocatalytic activity under the visible irradiation, i.e., those samples for which $E_{\mathrm{g}}<3.26 \mathrm{eV}$ (Table 3, columns 3 and 5). Under these conditions, it becomes possible to generate electron-hole pairs and initiate dye oxidation processes [25, 38]. The samples, having intermediate values of $E_{\mathrm{g}}$ but greater than $3.26 \mathrm{eV}$, exhibit low activity. $\mathrm{P}-25$ is such a sample. In this case, the absorption of visible light and the direct excitation of RhB molecules are very likely. Subsequent injection of an electron from the excited $\mathrm{RhB}$ molecules into the conduction band of a photocatalyst occurs. This is so-called photosensitization contributing to the initiation of photocatalytic process $[40,41]$. The kinetic curves of RhB degradation under visible irradiation presented in Fig. 8 illustrate different photocatalytic activity of the modified samples.

\section{Conclusions}

The MChT and MWT affect the crystalline structure of $\mathrm{ZrO}_{2}$ to varying degrees: they do not change its X-ray amorphous state in the former case and promote the formation of a monoclinic phase already at $150-190{ }^{\circ} \mathrm{C}$ in the latter case. A more open, namely meso-macroporous structure is formed in both cases. As a result, the specific surface area increases by $25 \%$ when gels are subjected to MWT and more than twice when gels are milled. A bi-porous structure is formed in the latter case. It is important that the structure transformations are accompanied by significant changes in electronic characteristics of modified $\mathrm{ZrO}_{2}$ : the absorption edge is shifted toward the visible region. The latter results in significant narrowing the band gap. Therefore, zirconium dioxide after MChT and MWT is characterized by a higher photodegradation rate of rhodamine $\mathrm{B}$ at the $\mathrm{UV}$ irradiation. Even more important is the fact that modified $\mathrm{ZrO}_{2}$ becomes photocatalytically active under visible illumination and more active than the reference titanium dioxide P-25.

Open Access This article is licensed under a Creative Commons Attribution 4.0 International License, which permits use, sharing, adaptation, distribution and reproduction in any medium or format, as long as you give appropriate credit to the original author(s) and the source, provide a link to the Creative Commons licence, and indicate if changes were made. The images or other third party material in this article are included in the article's Creative Commons licence, unless indicated otherwise in a credit line to the material. If material is not included in the article's Creative Commons licence and your intended use is not permitted by statutory regulation or exceeds the permitted use, you will need to obtain permission directly from the copyright holder. To view a copy of this licence, visit http://creativecommons.org/licenses/by/4.0/.

\section{References}

1. Mercera PDL, van Ommen JG, Doesburg EBM, Burggraaf AJ, Ross JRH. Zirconia as a support for catalysts. Appl Catal. 1991;71:363-73.

2. Yamaguchi T. Application of $\mathrm{ZrO}_{2}$ as a catalyst and a catalyst support. Catal Today. 1994;20(2):199-21717. https://doi. org/10.1016/0920-5861(94)80003-0.

3. Yadav GD, Nair JJ. Sulfated zirconia and its modified versions as promising catalysts for industrial processes. Micropor Mesopor Mat. 1999;33:1-48. https://doi.org/10.1016/S1387 -1811(99)00147-X.

4. Mahadavi S, Amini N, Merrikhpour H, Akhazari D. Characterization of bare and modifies nano-zirconium oxide $\left(\mathrm{ZrO}_{2}\right)$ and their applications as adsorbents for the removal of bivalenty heavy metals. Korean J Chem Eng. 2017;34:234-44. https://doi. org/10.1007/s11814-016-0259-3.

5. Neris AM, Ferreira JM, Fonseca MG, dos Santos IMG. Undoped tetragonal $\mathrm{ZrO}_{2}$ obtained by the Pechini method: thermal evaluation of tetragonal-monoclinic phase transition and application as catalyst for biodiesel synthesis. J Therm Anal Calorim. 2020. https ://doi.org/10.1007/s10973-020-09286-7.

6. French RH, Glass SJ, Ohuchi FS, Xu YN, Ching WY. Experimental and theoretical determination of the electronic structure and optical properties of three phases of $\mathrm{ZrO}_{2}$. Phys Rev. 1994;49:5133-42. https://doi.org/10.1103/PhysRevB.49.5133.

7. Ciuparu D, Ensuque A, Shafeev G, Bozon-Verduraz F. Synthesis and apparent bandgap of nanophase zirconia. J Mater Sci Lett. 2000;19(11):931-3. https://doi.org/10.1023/a:1006799701474.

8. Reddy CV, Babu B, Reddy IN, Shim J. Synthesis and characterization of pure tetragonal $\mathrm{ZrO}_{2}$ nanoparticles with enhanced photocatalytic activity. Ceram Int. 2018;44(6):6940-8. https://doi. org/10.1016/j.ceramint.2018.01.123.

9. Basahel SN, Ali TT, Mokhtar M, Narasimharao K. Influence of crystal structure of nanosized $\mathrm{ZrO}_{2}$ on photocatalytic degradation of methyl orange. Nanoscale Res Lett. 2015;10(1):73. https://doi. org/10.1186/s11671-015-0780-z.

10. Polisetti S, Deshpande PA, Madras G. Photocatalytic activity of combustion synthesized $\mathrm{ZrO}_{2}$ and $\mathrm{ZrO}_{2}-\mathrm{TiO}_{2}$ mixed oxides. Ind Eng Chem Res. 2011;50(23):12915-24. https://doi.org/10.1021/ ie200350f.

11. Leboda R, Charmas B, Sidorchuk VV. Physicochemical and technological aspects of the hydrothermal modification of complex sorbents and catalysts. Part 1. Modification of porous and crystalline structures. Adsorp Sci Technol. 1997;15(3):189-21414. https ://doi.org/10.1177/026361749701500305. 
12. Leboda R, Charmas B, Sidorchuk VV. Physicochemical and technological aspects of the hydrothermal modification of complex sorbents and catalysts. Part 2. Adsorp Sci Technol. 1997;15(3):215-30. https://doi.org/10.1177/026361749701500 306.

13. Skubiszewska-Zięba J. The impact of microwave energy on the results of silica gel hydrothermal modification. Adsorption. 2010;16:485-93. https://doi.org/10.1007/s10450-010-9249-7.

14. Koltsov I, Prześniak-Welenc M, Wojnarowicz J, Rogowska A, Mizeracki J, Malysa M, Kimmel G. Thermal and physical properties of $\mathrm{ZrO}_{2}-\mathrm{AlO}(\mathrm{OH})$ nanopowders synthesised by microwave hydrothermal method. J Therm Anal Calorim. 2017;131(3):227384. https://doi.org/10.1007/s10973-017-6780-8.

15. Predoana L, Atkinson I, Karaj DA, Odhiambo VO, Bakos LP, Nagyné Kovács T, Pandele-Cusu J, Petrescu S, Rusu A, Szilágyi IM, Pokol G, Zaharescu M. Comparative study of the thermal behavior of $\mathrm{Sr}-\mathrm{Cu}-\mathrm{O}$ gels obtained by sol-gel and microwaveassisted sol-gel method. J Therm Anal Calorim. 2020. https:// doi.org/10.1007/s10973-019-09205-5.

16. Byrappa K, Adschiri T. Hydrothermal technology for nanotechnology. Prog Cryst Growth Charact Mater. 2007;53:117-66. https ://doi.org/10.1016/j.pcrysgrow.2007.04.001.

17. Boldyrev VV. Hydrothermal reactions under mechanochemical action. Powder Technol. 2002;122:247-54. https://doi. org/10.1016/S0032-5910(01)00421-1.

18. Sidorchuk V, Leboda R, Maydannik D, Tertykh V. Peculiarities of hydrothermal treatment of silica in the form of hydrogel-xerogel. $\mathrm{J}$ Colloid Interface Sci. 1995;171:168-72. https://doi.org/10.1006/ jcis.1995.1163.

19. Skubiszewska-Zieba J, Khalameida S, Sydorchuk V. Comparison of surface properties of silica xero- and hydrogels hydrothermally modified using mechanochemical, microwave and classical methods. Colloids Surf A Physicochem Eng Asp. 2016;504:139-1553. https://doi.org/10.1016/j.colsurfa.2016.05.066.

20. Samsonenko M, Zakutevskyy O, Khalameida S, Charmas B, Skubiszewska-Zięba J. Influence of mechanochemical and microwave modification on ion-exchange properties of tin dioxide with recpect to uranyl ions. Adsorption. 2019;25:451-7. https://doi. org/10.1007/s10450-019-00036-2.

21. Khalameida S, Sydorchuk V, Skubiszewska-Zięba J, Charmas B, Skwarek E, Janusz W. Hydrothermal, microwave and mechanochemical modification of amorphous zirconium phosphate structure. J Therm Anal Calorim. 2017;128:795-806. https://doi. org/10.1007/s10973-016-5965-x.

22. Janusz W, Khalameida S, Skwarek E, Skubiszewska-Zieba J, Sydorchuk V, Charmas B. Modification of titanium phosphate precipitated from titanylsulfate. J Thermal Anal Calorim. 2019;135:2925-34. https://doi.org/10.1007/s10973-018-7611-2.

23. Šepelák V, Bégin-Colin $\mathrm{S}$, Le Caër G. Transformations in oxides induced by high-energy ball-milling. Dalton Trans. 2012;41(39):11927-48. https://doi.org/10.1039/c2dt30349c.

24. Yang G, Park SJ. Conventional and microwave hydrothermal synthesis and application of functional materials: A Review. Materials. 2019;12(7):1177. https://doi.org/10.3390/ma12071177.

25. Indris S, Amade R, Heitjans P, Finger M, Haeger A, Hesse D, Grünert W, Börger A, Becker KD. Preparation by high-energy milling, characterization, and catalytic properties of nanocrystalline $\mathrm{TiO}_{2}$. J Phys Chem B. 2005;109(49):23274-8. https://doi. org/10.1021/jp054586t.

26. Khalameida S, Samsonenko M, Skubiszewska-Ziẹba J, Zakutevskyy O. Dyes catalytic degradation using modified tin(IV) oxide and hydroxide powders. Adsorp Sci Technol. 2017;35:853-65. https://doi.org/10.1177/0263617417722251.
27. Leofanti G, Padovan M, Tozzola G, Venturelli B. Surface area and pore texture of catalysts. Catal Today. 1998;41:207-19. https ://doi.org/10.1016/S0920-5861(98)00050-9.

28. Sing KSW. Reporting physisorption data for gas/solid systems with special reference to the determination of surface area and porosity (Provisional). Pure Appl Chem. 1982;54(11):2201-18.

29. Rouquerol J, Baron G, Denoyel R, Giesche H, Groen J, Klobes P, Levitz P, Neimark AV, Rigby S, Skudas R, Sing K, Thommes M, Unger K. Recommendations for the characterization of porous solids. Pure Appl Chem. 1994;66:1739-58.

30. Gregg SJ, Sing KSW. Adsorption, Surface Area and Porosity. 2nd ed. London: Academic Press; 1982.

31. Adam J, Drumm R, Klein G, Veith M. Milling of zirconia nanoparticles in a stirred media mill. J Am Ceram Soc. 2008;91(9):283643. https://doi.org/10.1111/j.1551-2916.2008.02579.x.

32. Sing KSW, Everett DH, Haul RAW, Moscou L, Pierotti RA, Rouque'rol J, Siemieniewoska T. Reporting physisorption data for gas/solid systems with special reference to the determination of Surface Area and Porosity. Pure Appl Chem. 1985;57:603-19.

33. Xu C, Gao W. Pilling-Bedworth ratio for oxidation of alloys. Mater Res Innov. 2000;3(4):231-5. https://doi.org/10.1007/s1001 90050008.

34. Noubactep C. On the suitability of admixing sand to metallic iron for water treatment. Int J Environ Pollut Solut. 2013;1:22-36. https://doi.org/10.7726/ijeps.2013.1004.

35. Zhou XL, Yu GX, Tang C, Li CL, Wang JA, Novaro O, Lianos $\mathrm{ME}$, Cortés-Jácome MA. On the role of calcination temperature in $\mathrm{Pt}-\mathrm{SO}_{4}{ }^{2-} / \mathrm{ZrO}_{2}-\mathrm{Al}_{2} \mathrm{O}_{3}$ preparation and catalytic behaviors during the n-hexane hydroisomerization. Catal Lett. 2008;124(3-4):27783. https://doi.org/10.1007/s10562-008-9449-x.

36. Fan B, Zhang F, Li J, Chen H, Zhang R. Synthesis and crystallization behavior of $3 \mathrm{~mol} \%$ yttria partically stabilized zirconia (3Y-PSZ) nanopowders by microwave pyrolysis process. Mater Sci Eng. 2017;1:4-6. https://doi.org/10.4172/2169-0022.10003 27.

37. Sants V, Zeni M, Bergmann CP, Hohemberger JM. Correlation between thermal treatment and tetragonal/monoclinic nanostructured zirconia powder obtained by sol-gel process. Rev Adv Mater Sci. 2008;17:62-70.

38. Hoffmann MR, Martin ST, Choi W, Bahneman DW. Environmental applications of semiconductor photocatalysis. Chem Rev. 1995;95:69-966. https://doi.org/10.1021/cr00033a004.

39. Srinivasan NR, Majumdar P, Eswar NKR, Bandyopadhyaya R. Photocatalysis by morphologically tailored mesoporous silica (SBA-15) embedded with $\mathrm{SnO}_{2}$ nanoparticles: Experiments and model. Appl Catal A. 2015;498:107-16. https://doi.org/10.1016/j. apcata.2015.03.015.

40. Rauf MA, Ashraf SS. Fundamental principles and application of heterogeneous photocatalytic degradation of dyes in solution. Chem Eng J. 2009;151:10-8. https://doi.org/10.1016/j. cej.2009.02.026.

41. Wu T, Liu G, Zhao J, Hidaka H, Serpone N. Photoassisted degradation of dye pollutants. V. Self-photosensitized oxidative transformation of Rhodamine B under visible light irradiation in aqueous TiO2 dispersions. J Phys Chem B. 1998;102:5845-1. https:// doi.org/10.1021/jp980922c.

Publisher's Note Springer Nature remains neutral with regard to jurisdictional claims in published maps and institutional affiliations. 